\title{
U.S. Geological Survey - Virginia Department of Transportation: Bridge Scour Pilot Study
}

\section{Background}

Cost effective and safe highway bridge designs are required to ensure the long-term sustainability of Virginia's road systems. The streamflows that, over time, scour streambed sediments from bridge piers inherently affect bridge safety and design costs. To ensure safety, bridge design must anticipate streambed scour at bridge piers over the lifespan of a bridge. Until recently Federal Highway Administration (FHWA) guidance provided only for scour estimates of granular, noncohesive, highly erosive material yielding overestimates of scour potential in instances when streambed materials offer some resistance to scour. This study seeks to estimate stream power and streambed scour for these more resistive sites, with bridge piers potentially established in cohesive soil or erodible rock. This new knowledge may provide significant construction cost savings while ensuring design and construction of safe highway bridges.

\section{Purpose of the Study}

As research into properties of streambed materials has advanced, methods of evaluating scour that incorporate scour resistance are now included in new FHWA publications. Bridges with piers established in, or on, cohesive soil or erodible rock may now be designed so that the scour resistance of these materials is taken into account. These new and more complex design evaluations require knowledge of the duration of exposure of bed materials to scouring flows over the expected life of a bridge. The established standards for evaluating hydrologic processes employed by the Virginia Department of Transportation (VDOT) and readily available to the industry do not currently provide this type of information. As a step toward meeting this need, this pilot study seeks to estimate the (1) duration of specific streamflows and (2) potential cumulative stream power over the design lifespan of a bridge. This information may then be used to calculate comprehensive projections of anticipated scour rates specific to individual bridge piers. This new knowledge of cumulative scour may provide significant bridge construction cost savings while ensuring design and construction of safe highway bridges.

\section{Outcomes}

The U.S. Geological Survey is providing compilation, calculation, and summation of the hydrologic properties needed to determine potential rates of streambed scour at study test sites. Changing instantaneous streamflows affect streambed scour. Statistical methods that include Monte Carlo sampling processes allow use of instantaneous streamflows measured since 1990 to estimate instantaneous streamflows across the full range of daily streamflow measurements made at each study site. These hydrologic statistics (fig. 1) and statistical methods (fig. 2) provide the data for hydrologic modeling (fig. 3), which will assist in estimating future cumulative streambed scour at specific bridge pier locations over

Figure 1. Example output for instantaneous streamflow discharge measurements associated with daily streamflow discharge measurements. (DV, daily discharge)

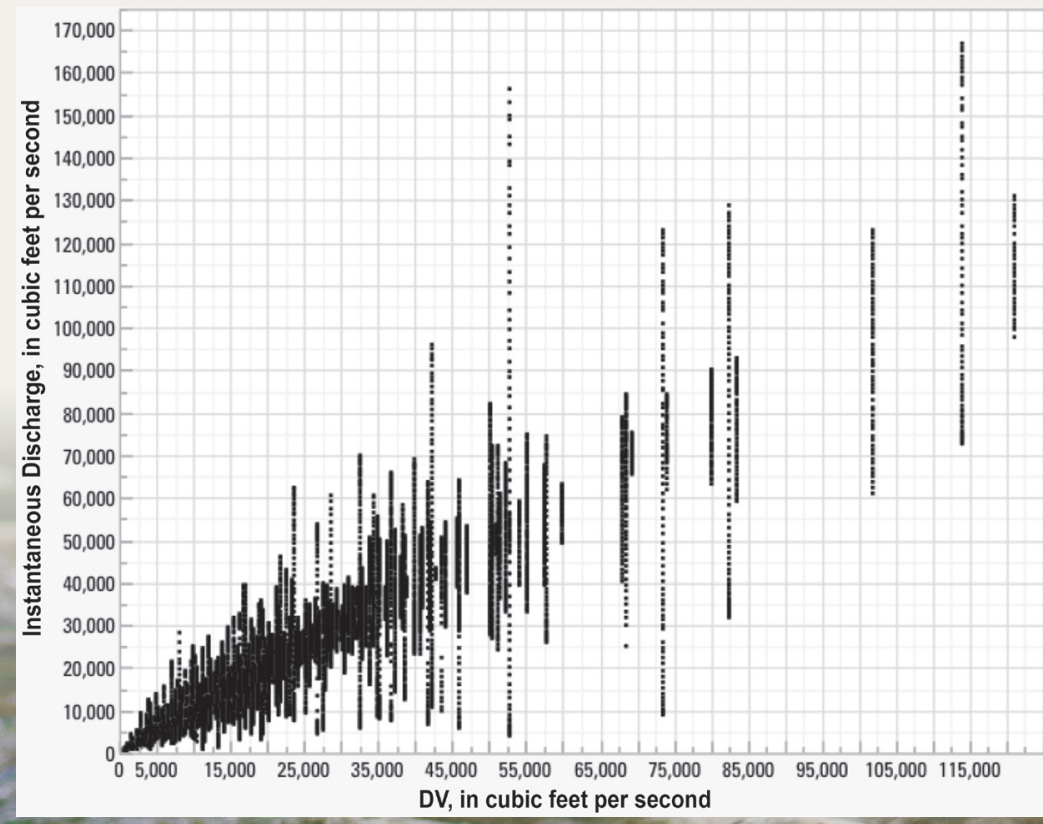




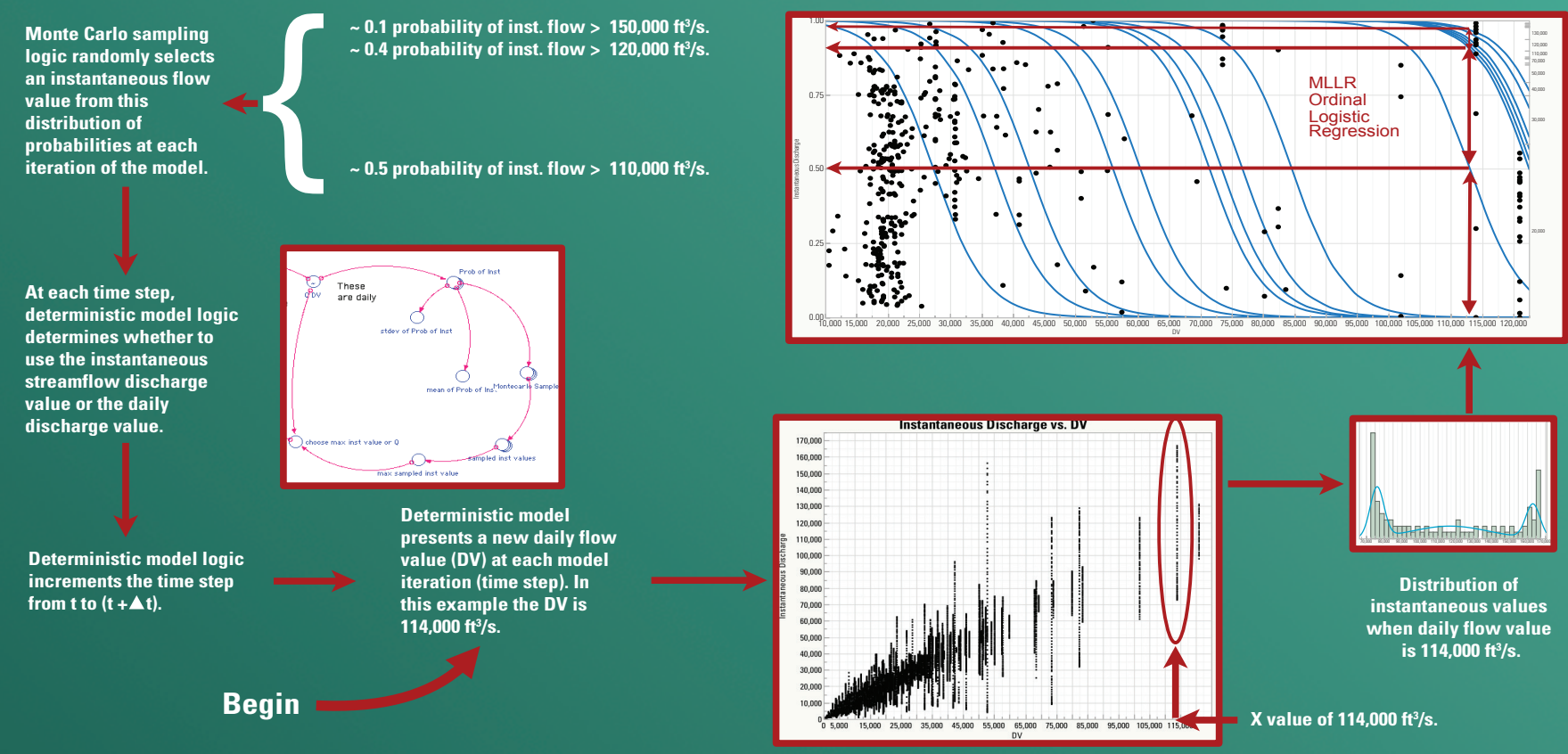

Figure 2. An overview of statistical methods used when sampling instantaneous flows. ( $\mathrm{ft}^{3} / \mathrm{s}$, cubic feet per second; inst., instantaneous; MLLR, Maximum Likelihood Logistic Regression)

their projected design lifespan. VDOT is providing the non-hydrologic elements essential to determining potential rates of streambed scour, such as bridge location and design specifications, attributes of cohesive soils associated with bridge piers, geotechnical attributes of bridge scour computations, and preferred specifications and methods for estimating soil scour.

Figure 3. An example of site-specific hydrologic modeling using instantaneous streamflows. Daily streamflow discharge measurements and Monte Carlo selected instantaneous streamflow discharge measurements are displayed.

\section{Study Deliverables}

- Analysis and evaluation of daily and instantaneous stream discharge data.

- Hydrologic design products.

- Hydraulic geometry characteristics.

- Evaluation of discharge probabilities.

- Simulation tools for probabilistic and deterministic analyses of dischargeduration scenarios.

\section{By Samuel H. Austin}

Publishing support provided by the West Trenton Publishing Service Center

\section{For more information, contact:}

Virginia and West Virginia

Water Science Center

1730 East Parham Road

Richmond, VA 23228

https://www.usgs.gov/centers/va-wv-water.

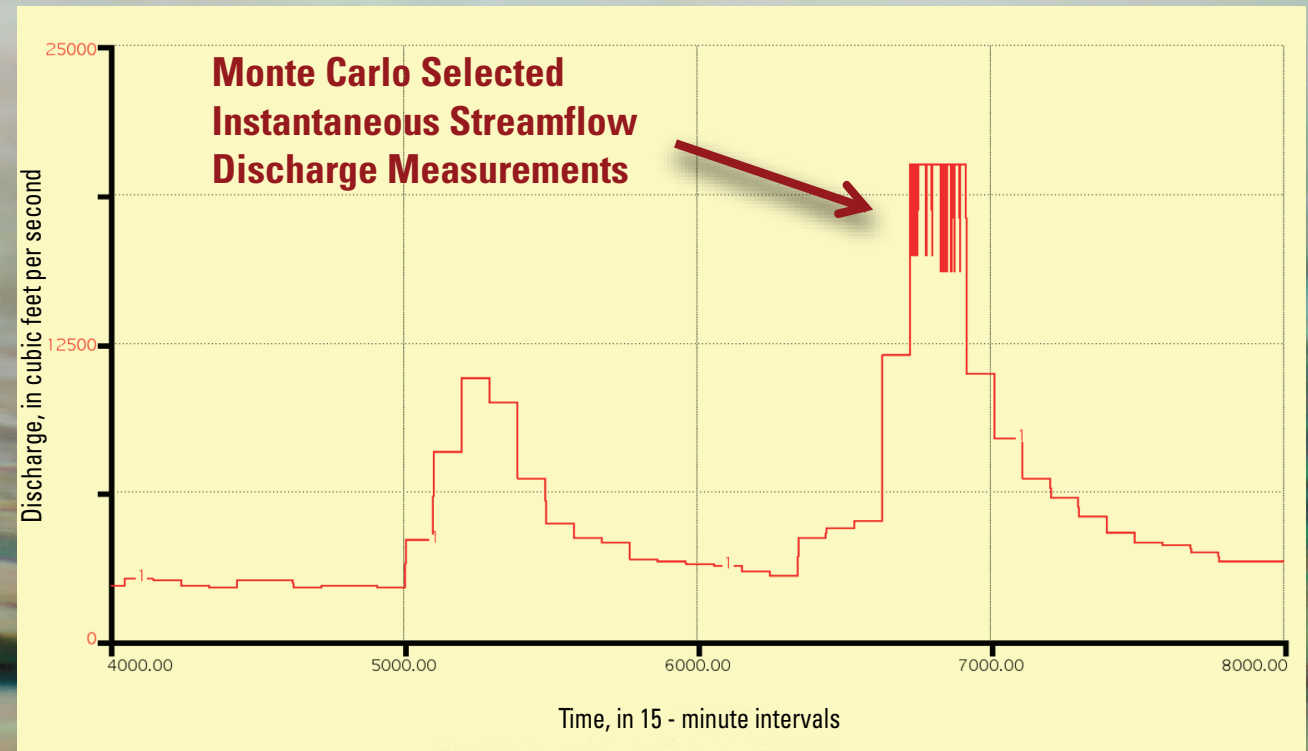

